\title{
A GBP 130 Derived Peptide from Plasmodium falciparum Binds to Human Erythrocytes and Inhibits Merozoite Invasion in Vitro
}

\author{
Jorge E Suarez, Mauricio Urquiza, Hernando Curtidor, Luis E Rodriguez, Marisol \\ Ocampo, Elizabeth Torres, Fanny Guzman, Manuel Elkin Patarroyo ${ }^{+}$
}

\author{
Instituto de Inmunología, Hospital San Juan de Dios, Universidad Nacional de Colombia, AA 44709, \\ Bogotá, Colombia
}

The malarial GBP 130 protein binds weakly to intact human erythrocytes; the binding sites seem to be located in the repeat region and this region's antibodies block the merozoite invasion. A peptide from this region (residues from 701 to 720 ) which binds to human erythrocytes was identified. This peptide named 2220 did not bind to sialic acid; the binding site on human erythrocyte was affected by treatment with trypsin but not by chymotrypsin. The peptide was able to inhibit Plasmodium falciparum merozoite invasion of erythrocytes. The residues $F_{701}, K_{703}, L_{705}, T_{706}, E_{713}$

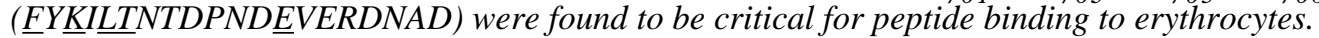

Key words: Plasmodium falciparum - GBP 130 - binding assay

Interactions between Plasmodium falciparum merozoite and erythrocyte proteins are essential for the parasite's survival. Inhibition of these interactions is one of the main strategies for malaria control. Merozoite proteins involved in erythrocyte recognition, binding and invasion are specific targets for the development of effective weapons against malaria (Camus \& Hadley 1985, Kochan et al. 1986, Perkins \& Rocco 1988).

One of these erythrocyte binding proteins is the glycophorin binding protein (GBP 130) (Perkins 1984), which contains 11 highly conserved 50-residue-long repeats and a charged 225-residue-long $\mathrm{N}$-terminal region. GBP 130 binds weakly intact human erythrocytes and this binding is not significantly modified by erythrocyte neuraminidase treatment (Perkins 1988). GBP 130 binds to glycophorin coupled to an acrylamide matrix (Perkins 1984). Although the specificity of its binding has been questioned (Van Scharavendijk et al. 1987), the binding sites seem to be located in the repeat region, since this region alone is able to bind to glycophorin (Kochan et al. 1986). Antibodies raised against a

This research project was supported by the Presidency of the Republic of Colombia, the Ministry of Public Health, Colciencias and the German Leprosy Relief Association.

${ }^{+}$Corresponding author. Fax: +57-1-280.3999. E-mail: jorgeess@hotmail.com

Received 13 September 1999

Accepted 22 March 2000 recombinant fusion protein containing 4.5 of the 50-amino acid repetitive units from GBP 130 inhibit in vitro merozoite invasion into erythrocytes (Kochan et al. 1986). Furthermore, immunization of splenectomized Saimiri monkeys with parasite proteins induces a protective immune response against P. falciparum (Dubois et al. 1984), in which the main antigen is a $96 \mathrm{kDa}$ thermostable protein that was first described in 1984 as GBP 130 (Bonnefoy et al. $1988,1994)$. GBP 130 is also recognized by antibodies involved in the formation of "Immune Clusters of Merozoites" when the P. falciparum parasites are cultured in the presence of immune sera from Aotus monkeys (Lyon et al. 1986, 1989, Chulay et al. 1987). On the contrary, a three repeat (GBP3R) recombinant protein was not recognized by these antibodies; also immunization of Aotus monkeys with this protein provided no protection whatsoever (Aronson et al. 1991).

In order to identify GBP 130 sequences relevant to its binding to human erythrocytes, sequential non-overlapping 20 mer peptides, spanning the entire sequence (Kochan et al. 1986), were synthesized and tested in erythrocyte binding assay. A peptide (named 2220) with a high binding activity to erythrocytes was identified. This peptide has a $150 \mathrm{nM}$ affinity constant and is located in the GBP 130 repeat region. The binding activity of this peptide is not dependent on erythrocyte-sialic acid. The binding of this peptide to trypsin treated erythrocyte is affected, but not by chymotrypsin. This peptide also inhibited merozoite invasion of erythrocytes. 


\section{MATERIALS AND METHODS}

Peptide synthesis - Peptides were synthesized by the solid phase method (Merrifield 1963, Houghten 1985) with 100 mg p-methyl benzyhydrylamine resin (substitution $0.74 \mathrm{meq}^{-1}$ ). Standard $\mathrm{N} \alpha \mathrm{t}$-Boc protected amino acids were employed (Bachem). Peptides were cleaved by the Low-High HF technique (Tam et al. 1983), purified by RP-HPLC and freeze-dried.

Amino acid analysis was performed on all peptides and amino acid sequence on those having high binding activity. In order to allow radiolabeling of peptides which did not contain a Tyr residue, the underlined residue was replaced with Tyr (Fig. 1); replacements are based on volumetric and charge analysis.

Radiolabeling - Peptides were labeled with ${ }^{125_{I}}$ by the chloramine T method (Urquiza et al. 1996);

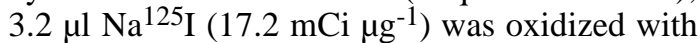
$28 \mu \mathrm{g}$ chloramine $\mathrm{T}$ and added to $5 \mu \mathrm{g}$ of peptide. The reaction was stopped by addition of $14 \mu \mathrm{g}$ sodium bisulfite in isotonic PBS (pH 7.4). The radiolabeled peptide was purified by passage through a sephadex G-10 column.

Screening assay - Increasing concentrations of radiolabeled peptide $(16-100 \mathrm{nM})$ were added to a human erythrocyte suspension $\left(3 * 10^{8}\right.$ cells $)$, in the absence (total binding) or presence (non-specific binding) of unlabeled peptide $(1.25 \mu \mathrm{M})$, and incubated for $1 \mathrm{~h}$ at room temperature (Urquiza et al. 1996). After incubation, cells were washed five times with isotonic PBS. The specific binding was calculated as the difference between total and non-specific binding. For each peptide, the slope of the specific binding curve (specific bound CPM/ total added CPM) was calculated (Fig. 1). Based on previous studies, peptides with slope values greater than or equal to $2 \%$, were considered as being high specific binding activity (HSBA) (Urquiza et al. 1996).

The binding assay with erythrocytes from other species (Aotus monkeys, rabbits, horses, goats, and chickens) was performed under the same experimental conditions. For saturation assays, $3 * 10^{7}$ cells were incubated in $140 \mu \mathrm{l}$ and radiolabeled peptide concentration ranged from 20 to $400 \mathrm{nM}$.

Treatment of erythrocytes with neuraminidase - Erythrocytes (20\% hematocrit, in buffer containing $5 \mathrm{mM}$ sodium acetate, $140 \mathrm{mM} \mathrm{NaCl}, 10 \mathrm{mM}$ $\mathrm{CaCl}_{2}$, and 0.1 mM PMSF, pH 5.1) were treated with $250 \mu \mathrm{U}$ neuraminidase (ICN 9001-67-6) per ml of packed cells at $37^{\circ} \mathrm{C}$ for $1 \mathrm{~h}$. Finally the cells were washed with TBS (Camus \& Hadley 1985) and used in binding assay.

Treatment of erythrocytes with trypsin and chymotrypsin - Erythrocytes [20\% hematocrit in TBS buffer (5 mM Tris-HCl, $140 \mathrm{mM} \mathrm{NaCl}, \mathrm{pH} 7.4)]$ were treated with trypsin (Sigma T-1005) or chymotrypsin (Sigma C-4129) at a final concentration of $100 \mu \mathrm{g}$ $\mathrm{ml}^{-1}$ at $25^{\circ} \mathrm{C}$ for $1 \mathrm{~h}$. They were then washed with TBS buffer containing $0.1 \mathrm{mM}$ EDTA and $0.1 \mathrm{mM}$ PMSF (Camus \& Hadley 1985). These erythrocytes were used in binding assay with ${ }^{125}$ I-labeled peptide 2220.

Competition binding assay - In order to identify the residues involved in peptide binding to erythrocytes, a competition binding assay was carried out with peptide 2220 glycine analogues (Fig. 4). Human erythrocytes $\left(1 * 10^{8}\right)$ in $100 \mu$ l were incubated with $20 \mathrm{nM}$ of ${ }^{125}$ I-labeled peptide 2220 and with 0,100 and $800 \mathrm{nM}$ of each non-radiolabeled analogue peptide for $1 \mathrm{~h}$ at room temperature. The erythrocytes were then washed five times with 25 volume of PBS. The assay was done in triplicate. It was considered that a critical amino acid replacement had taken place in any peptide analogue which was not able to inhibit at least $50 \%$ of the ${ }^{125}$ I-labeled 2220 peptide binding.

Invasion and development inhibition assays The peptides were tested for their ability to inhibit erythrocyte invasion by merozoites. For this purpose in vitro $P$. falciparum FCB-2 strain cultures were used. A synchronized culture, in schizont stage (Trager \& Jensen 1976), was seeded in 96-well plates with non-infected erythrocytes and with the peptide $(200 \mu \mathrm{M}$ final concentration, a final hematocrit of $1.5 \%$ and a final parasitemia of $1.2 \%$ ). After $18 \mathrm{~h}$, the culture supernatant was removed and complete media was added with $1.33 \mu \mathrm{Ci} \mathrm{ml} \mathrm{m}^{-1}$ of ${ }^{3} \mathrm{H}$ hypoxanthine. Plates were then incubated for $30 \mathrm{~h}$ and harvested in fiberglas filters. To determine the development inhibition capacity, a simultaneous assay was performed under similar conditions, but peptides were added at the ring-stage after synchronization. Schizonts were harvested after $30 \mathrm{~h}$ of development inhibition test incubation. Two criteria were used to assess invasion and development: (1) the amount of newly formed rings was determined by measuring the incorporation of ${ }^{3} \mathrm{H}$ hypoxanthine (metabolic labeling of rings); (2) alternatively, the number of newly formed rings was determined by microscopic examination in Giemsa stained thin smears. Routinely, 10,000 erythrocytes were examined and the percentage was calculated.

\section{RESULTS}

Human erythrocytes binding peptides - In the GBP-130 peptide screening binding assay, according to Urquiza et al. (1996), three patterns were found: high specific binding peptides, non-specific binding peptides and low or non-binding peptides. Only one high specific binding peptide was found, and named 2220 (Fig. 1). This peptide is located in the GBP-130 repeat sequence, for which binding 
activity has already been reported (Kochan et al. 1986). Some other peptides $(2204,2208,2212,2217)$, with very similar sequences to peptide 2220 (RDN is substituted by RRN), show lower binding activities than peptide 2220 . Peptides which only share the $\mathbf{N}$-terminal $(2201,2206,2209,2214,2222)$ or the C-terminal $(2202,2210,2215,2218,2223)$ sequence with peptide 2220 showed no specific binding to erythrocytes.

In order to investigate whether the peptide labeling, which introduces an iodine atom into a tyrosine residue, affected its interaction with human erythrocytes, an additional assay was carried out with peptide 2220 labeled with non-radioactive $\mathrm{NaI}$. Fig. 2 shows that both iodinated and non-iodinated peptides identically displaced the radiolabeled ligand. Therefore, iodinated tyrosine can be excluded as significantly altering the erythrocytepeptide interaction.

A saturation binding assay was performed for peptide 2220 (Fig. 3). The Hill plot, obtained by transformation of experimental data, is shown in the inset. Using saturation and Hill analysis, a 150 $\mathrm{nM}$ dissociation constant and a Hill coefficient of 2 were calculated and each cell was determined to have 8,000 binding sites.

\begin{tabular}{|c|c|c|c|c|}
\hline $\begin{array}{l}\text { Peptide } \\
\text { Number }\end{array}$ & Sequence & Residues & $\begin{array}{l}\text { Binding activity } \\
1.0\end{array}$ & 2.0 \\
\hline 2189 & M R L S K V S D I K S T G V S N Y K N F & $1-20$ & & \\
\hline 2190 & NSKNSSK Y S L M E V S K K NEKK & $21-40$ & & \\
\hline 2191 & N S L G A F H S K K K I L L I I F G I I & $41-60$ & & \\
\hline 2192 & 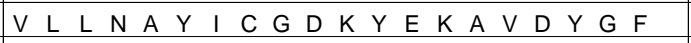 & $61-80$ & & \\
\hline 2193 & $R E S R \Psi L A E G E D T C A R K E K T T$ & $81-100$ & & \\
\hline 2194 & 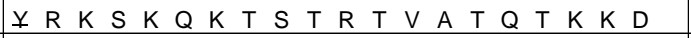 & $101-120$ & & \\
\hline 2195 & $E E N K S \vee V T E E Q K V E S D Y E K Q$ & $121-140$ & & \\
\hline 2196 & K R T K K V V K K Q I N $Y$ G D T E N Q K & $141-160$ & & \\
\hline 2197 & $E G K N V K K V Y K K E K K K E E S G K$ & $161-180$ & & \\
\hline 2198 & $P E E N K H A N E A S K K K E P K A Y K$ & $181-200$ & & \\
\hline 2199 & $V S Q K P S T S T R S N N E V K Y R A A$ & $201-220$ & & \\
\hline 2200 & $S N Q E T L T S A D P E G Q \quad I M R E Y A$ & $221-240$ & & \\
\hline 2205 & $D N K E D L T S A D P E G Q I M R E Y A$ & $321-340$ & & \\
\hline 2213 & NKE D L T S A D P E G Q I M R E Y A A & $521-540$ & & \\
\hline 2221 & 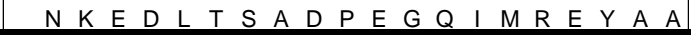 & $721-740$ & & \\
\hline 2203 & $P E G Q I M R E Y A S D P E Y R K H$ L E & $281-300$ & & \\
\hline 2207 & $P E G Q \mid M R E Y A A D P E Y R K H L E$ & $381-400$ & & \\
\hline 2211 & E G K I M R E Y A A D P E Y R K H L E I & $481-500,581-600$ & & \\
\hline 2219 & $E G Q \quad$ I $M R E$ E A S D P E Y R K H L E I I & $681-700$ & & \\
\hline 2201 & 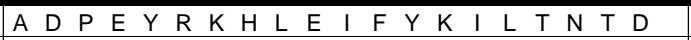 & $241-260$ & & \\
\hline 2206 & A D P E Y R K H L E V F H K I L T N T D & $341-360$ & & \\
\hline 2209 & A D P E Y R K H L E V F H K I L T N T D & $441-460$ & & \\
\hline 2214 & D P E Y R K K H L E I F Y K K I L & $541-560$ & & \\
\hline 2222 & D P E Y R K K H L E I F H K I L & $741-760$ & & \\
\hline 2204 & 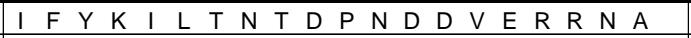 & $301-320$ & & \\
\hline 2208 & $\underline{Y} F \mathrm{H} K \mathrm{~K}$ I L T N T D P N D E V E R R N A & $401-420$ & & \\
\hline 2212 & F H K $K$ Y L T N T D P $P$ N D E V V E R R $R$ N A D & $501-520$ & & \\
\hline 2217 & $\underline{Y} \mathrm{H} K \mathrm{~K} \quad \mathrm{I} L \mathrm{~L} N \mathrm{~N}$ D $\mathrm{P} N \mathrm{~N}$ D E V E R R N A D & $601-620$ & & \\
\hline 2220 & $F \quad Y K I L T N T D P N D E V E R D N A D$ & $701-720$ & & \\
\hline 2202 & $P N D E V E R R N A D N K E D Y T S A D$ & $261-280$ & & \\
\hline 2210 & $P N D E V E R R N A D N K E Y T S S D V$ & $461-480$ & & \\
\hline 2215 & $N D E V E R R N A D N K E E Y T S S D P$ & $561-580$ & & \\
\hline 2218 & $N D E V E R R N A D N K E D Y T S A D P$ & $661-680$ & & \\
\hline 2223 & $N D E V E R Q N A D N Q E A \not$ & $761-774$ & & \\
\hline
\end{tabular}

Fig. 1: GBP 130 synthetic peptides' specific binding activity to human erythrocytes. Amino acid sequences are given in the left column. Binding activity: is the slope value of specific binding curve. Underlined amino acids were substituted with Tyr to allow radiolabeling. Each one of the black bars represents the slope of the specific binding curve, which is named high specific binding activity (HSBA). Peptides with HSBA $\geq 2 \%$ were considered as high specific binding peptides to erythrocytes, since these peptides recognize more than 200 specific binding sites per cell at low concentrations of radiolabeled peptide $(200 \mathrm{nM})$. 


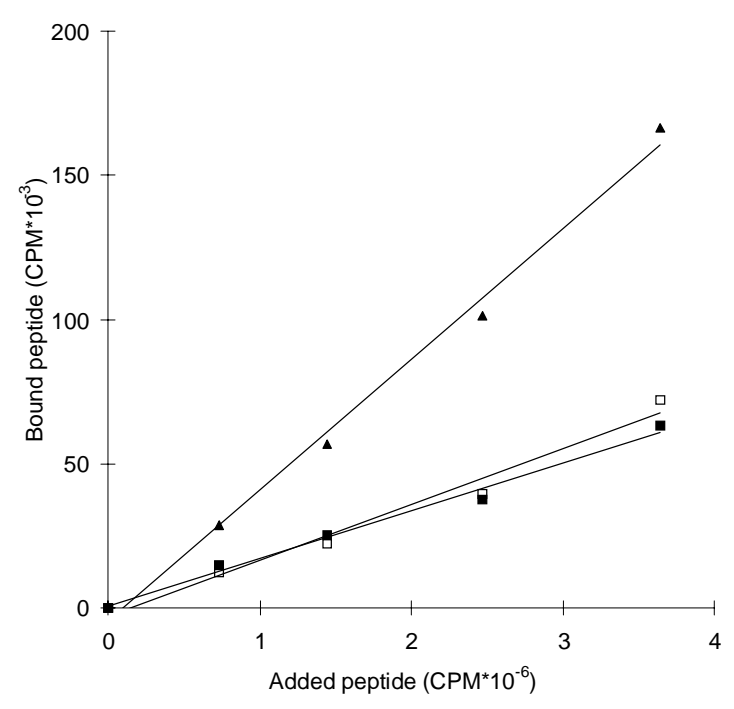

Fig. 2: peptide ${ }^{125} \mathrm{I}-2220$ binding to human erythrocyte. Total binding: binding to erythrocyte in absence of competition ( $\boldsymbol{\Delta}$ ). Non specific-binding: binding in presence of non-labeled peptide $(\square)$. Non specific binding in presence of peptide iodinate with non-radioactive $\mathrm{NaI}(\boldsymbol{\square})$.

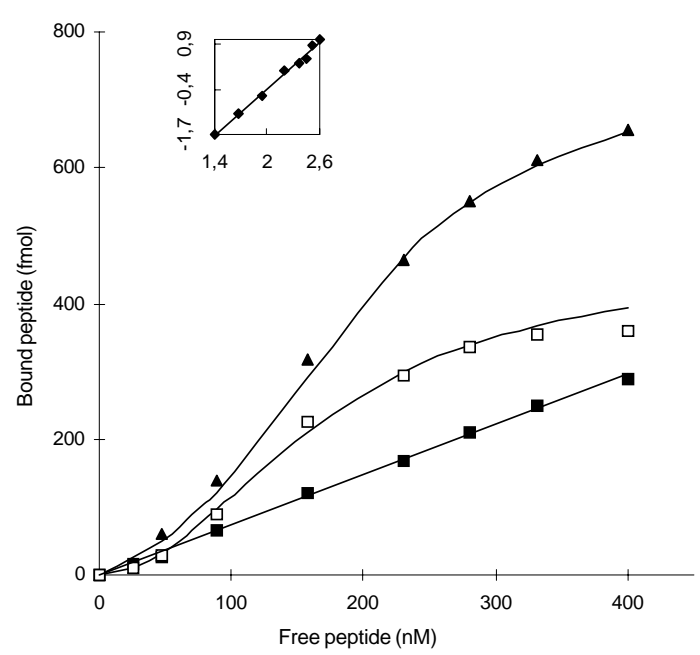

Fig. 3: saturation curve for peptide 2220. The graph shows the total ( $\boldsymbol{\Delta}$ ) binding, non-specific ( $\boldsymbol{\square})$ binding and specific ( $\square$ ) binding of the radiolabeled peptide to human erythrocytes. In the Hill plot (inset graph) the axis are: the abscissa is $\log \mathrm{F}$, and the ordinate is $\log (\mathrm{B} / \mathrm{B} \max -\mathrm{B})$. B: fmol bound peptide; Bmax: maximum fmol bound peptide; $\mathrm{F}$ : nM free peptide

Peptide 2220 and interaction with enzyme treated erythrocytes - In order to determine whether the peptide 2220 interacts with sialic acid or sialoglycoproteins, binding assays were performed with enzyme treated erythrocytes. Table I shows the percentages of specific binding compared to peptide binding of normal human erythrocytes.
Human erythrocytes treated with neuraminidase showed a $373 \%$ increase in specific binding for peptide 2220. However, human erythrocytes treated with trypsin showed markedly lower affinity for peptide 2220 , with a reduction to $35 \%$. It was also noted that, when human erythrocytes were treated with chymotrypsin, there was no effect on peptide 2220 specific binding.

Peptide 2220 bound mainly to human erythrocytes - Peptide 2220 was assayed with erythrocytes of different species with the aim of determining if the binding is species specific (Table I). Peptide 2220 possesses a higher specific binding to human erythrocytes than to erythrocytes from other species. Aotus and rabbit erythrocytes showed specific binding values of $59 \%$ and $44 \%$ respectively, compared to human erythrocytes. No binding was observed to goat, horse or chicken erythrocytes.

\section{TABLE I}

Binding of 2220 peptide to enzyme treated human erythrocyte and non-human erythrocytes

\begin{tabular}{lc}
\hline Erythrocytes & Specific binding (\%) \\
\hline Humans & \\
$\quad$ non-treated & $100 \pm 8$ \\
neuraminidase & $373 \pm 31$ \\
$\quad$ trypsin & $35 \pm 4$ \\
$\quad$ chymotrypsin & $95 \pm 9$ \\
\hline Aotus & $59 \pm 6$ \\
Rabbits & $44 \pm 7$ \\
Goats & $0 \pm 4$ \\
Horses & $0 \pm 2$ \\
Chickens & $8 \pm 4$ \\
\hline
\end{tabular}

Critical residues for peptide-erythrocyte interaction - The importance of each residue in the binding of peptide 2220 to erythrocytes was determined by analyzing the ability of glycine analogs to inhibit the binding of the unmodified peptide (competition binding assay, Fig. 4). Residues $\mathrm{F}_{701}$, $\mathrm{K}_{703}, \mathrm{~L}_{705}, \mathrm{~T}_{706}$ and $\mathrm{E}_{713}$ were critical, since the replacement of any of these amino acids dramatically reduced their binding affinity (Fig. 4).

Effect on in vitro peptide 2220 P. falciparum cultures - To determine whether the peptide 2220 is biologically relevant, in vitro invasion and development inhibition assays were performed. Both assays were performed in triplicate and six peptides were used as controls: peptides 2189 and 2197 (medium specific-binding); peptides 2204 and 2208 (low specific-binding); and peptides 2214 and 2215 (non-binding). As shown in Table II, the invasion process is inhibited only by peptide 2220 (91\% inhibition). The slides of this assay, staining with 
TABLE II

Inhibition of parasite invasion and development to erythrocyte by GBP 130 peptides

\begin{tabular}{|c|c|c|c|c|c|c|c|c|c|}
\hline \multirow{3}{*}{$\begin{array}{l}\text { Binding } \\
\text { activity }\end{array}$} & \multirow{3}{*}{$\begin{array}{l}\text { Peptides } \\
(200 \mu \mathrm{M})\end{array}$} & \multicolumn{4}{|c|}{ Inhibition of invasion } & \multicolumn{4}{|c|}{ Inhibition of development } \\
\hline & & \multicolumn{2}{|c|}{${ }^{3}$ H-hypoxanthine } & \multicolumn{2}{|c|}{ Giemsa } & \multirow{2}{*}{\multicolumn{2}{|c|}{${ }^{3} \mathrm{H}$-hypoxanthine }} & \multicolumn{2}{|c|}{ Giemsa } \\
\hline & & $\%$ & $\mathrm{SD}$ & $\%$ & $\mathrm{SD}$ & $\%$ & & $\%$ & SD \\
\hline High & 2220 & 91 & \pm 7 & 86 & \pm 9 & 7 & \pm 17 & 2 & \pm 5 \\
\hline \multirow[t]{2}{*}{ Medium } & 2189 & 0 & \pm 4 & 0 & \pm 6 & 59 & \pm 9 & 67 & \pm 8 \\
\hline & 2197 & 0 & \pm 5 & 2 & \pm 4 & 0 & \pm 1 & 1 & \pm 1 \\
\hline \multirow[t]{2}{*}{ Low } & 2204 & 0 & \pm 1 & 2 & \pm 2 & 0 & \pm 2 & 2 & \pm 3 \\
\hline & 2208 & 0 & \pm 2 & 0 & \pm 1 & 5 & \pm 3 & 0 & \pm 2 \\
\hline \multirow[t]{2}{*}{ No-binding } & 2214 & 0 & \pm 3 & 4 & \pm 4 & 0 & \pm 1 & 1 & \pm 2 \\
\hline & 2215 & 0 & \pm 9 & 0 & \pm 3 & 0 & \pm 4 & 0 & \pm 1 \\
\hline Control & Chloroquine & 98 & \pm 17 & 100 & \pm 11 & 99 & \pm 4 & 100 & \pm 10 \\
\hline
\end{tabular}

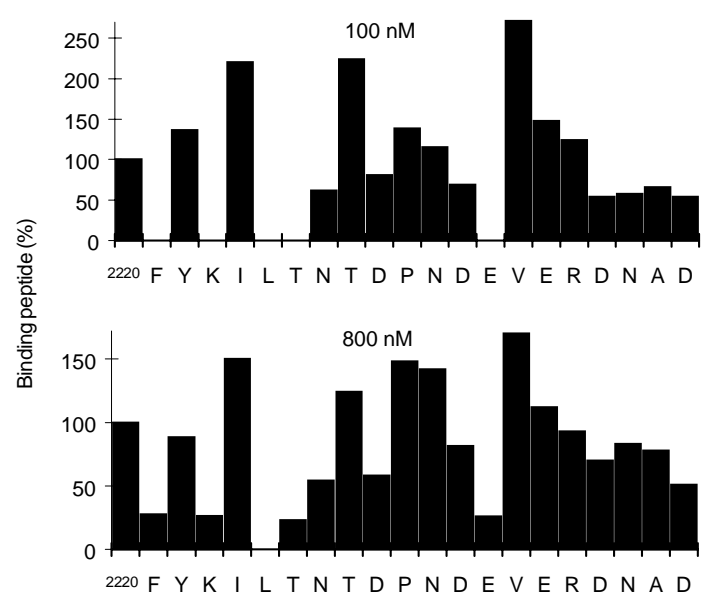

Residue

Fig. 4: specific binding to erythrocytes of peptide 2220 in competition assays with glycine analog peptides. The height of the black bars is proportional to the binding inhibition of the original radiolabeled peptide $(20 \mathrm{nM})$ by the original or peptide unlabeled analogues $(100$ and $800 \mathrm{nM})$. The letter at the bottom represents the amino acid changed by glycine.

Giemsa show that the parasites in the slide of peptide 2220 has the same morphology of the control, but the number of parasited erythrocytes was diminished. None of the control peptides showed any effect on P. falciparum parasite invasion. One control peptide (2189) markedly affected the development of the parasite (59\%), but did not inhibit invasion. This suggests that it may have a toxic effect on the intracellular parasite, but is not capable of interacting with erythrocyte proteins to block the invasion process.

\section{DISCUSSION}

Merozoite surface proteins play an important role in erythrocyte invasion, since they determine the first contact between erythrocyte and merozoite. Among these, GBP 130 has been implicated as being an erythrocyte binding protein in merozoites (Perkins 1984, 1988). Peptide 2220 was identified as being a part of the GBP 130 sequence which binds specifically to erythrocytes. This peptide belongs to the repeat region which binds to human erythrocytes; antibodies against this region inhibited in vitro erythrocyte invasion by merozoites (Kochan et al. 1986). Peptides 2204, 2208, 2212, 2217 and 2220 have a very similar sequence, including the residues critical for binding to erythrocytes. However, the 2220 peptide has the highest binding affinity. The change of $\mathrm{R}$ for $\mathrm{D}$ in position 717 increases the affinity of peptide 2220 to erythrocytes.

The interaction between peptide 2220 and erythrocytes is charge-independent, since peptides 2202 and 2205, which have a similar charge, did not bind specifically to erythrocytes. Consequently, the amino acid sequence is the determinant factor in the binding. Peptide 2220, iodinated with non-radioactive $\mathrm{NaI}$, displaced the radiolabeled ligand identically to displacement produced by the nonlabeled peptide (Fig. 2), showing that the modification caused by iodination of the peptide does not affect this peptide's interaction with erythrocytes. A $150 \mathrm{nM}$ affinity constant shows that the interaction between peptide 2220 and erythrocytes is very strong. This interaction could be mediated by saltbridges, since peptide 2220 has a high proportion of charged amino acids (8/20) and the $\mathrm{E}_{713}$ amino acid is critical to binding. A Hill coefficient of 2 suggests positive cooperativity. 
Peptide 2220 shows a high increase in specific binding to neuraminidase treated erythrocytes (Table I), indicating that the interaction does not involve sialic acid molecules. This agrees with previous observations, which demonstrate that GBP 130 receptors are not dependent on sialic acid (Perkins 1988). The binding of peptide 2220 to erythrocytes was affected by the treatment with trypsin and not by chymotrypsin. As trypsin cleaves the external proteic part of glycophorin $\mathrm{A}$ and $\mathrm{C}$ (Pasvol 1984), it is possible that glycophorin A, C or other related molecules act as a receptor for this peptide. However, as the binding was not completely abrogated by trypsin treatment, other proteins (such as glycophorin B) could be involved in the binding. The membrane receptor of peptide 2220 has not been identified, although it is known that its binding activity is sensitive to trypsin treatment.

Binding competition assays with peptide 2220 glycine analogues show that some amino acids (FYKILTNTDPNDEVERDNAD) were critical in the binding; probably these residues are not only involved in direct binding interactions (salt-bridges and hydrophobic), but could also be essential for the induction of the tridimensional structure required for binding. In some cases the replacement of 2220 residues by glycine led to peptides with higher binding affinity $\left(\mathrm{I}_{704}, \mathrm{P}_{710}, \mathrm{~N}_{711}, \mathrm{~V}_{714}\right)$. Probably these residues' side chains hinder optimal 2220 peptide-receptor interactions. Substitution of two different threonine residues $\left(\mathrm{T}_{706}\right.$ and $\mathrm{T}_{708}$ ) has a very different effect on peptide binding (Fig. 4). This further emphasizes that peptide 2220 binding is highly dependent on its primary structure, and not only on a particular amino acid composition.

The binding assays with peptide 2220 and erythrocytes from different species (Table I) showed that this peptide binds to human erythrocytes with higher affinity than to erythrocytes from other species. However, it also interacts with Aotus monkeys' erythrocytes, albeit to a lesser extent. This might explain why both species are susceptible to P. falciparum infection. Peptide 2220 also binds significantly to rabbit erythrocytes. It has been demonstrated that some proteins involved in merozoite invasion are able to bind to rabbit erythrocytes (Orlandi et al. 1990), but $P$. falciparum merozoites do not invade these erythrocytes (Breuer et al. 1983). Probably the binding domain of the peptide receptor on the erythrocyte is different in the studied species, which will change the affinity constant of this interaction.

Two assays were carried out in order to test the peptide effect on in vitro cultures of P. falciparum. In one assay, peptide was added before merozoites were released at the schizont stage. In this assay, peptide 2220 inhibited invasion by $91 \%$. The peptide may affect merozoite release or erythrocyte invasion. However, we did not see delay in parasite growth or death parasites. This could be indicating that peptide 2220 may compete for the receptor sites on the erythrocyte and block the merozoite-invasion. In another assay, when peptide was added after invasion, ring stage peptide 2220 did not affect parasite development. However, the difference in membrane permeability between ring stage and schizont stage restricts the interpretation of this results. The peptide concentration needed for invasion-inhibition was higher than the affinity constant value; this may be due to higher GBP 130 affinity than peptide 2220 , or because the effective concentration is diminished by proteolytic degradation. Interestingly, peptide 2220 belongs to a repeat region which binds to glycophorin and elicits antibodies able to block merozoite invasion of erythrocytes (Kochan et al. 1986).

\section{REFERENCES}

Aronson NE, Silverman C, Wasserman GF, Kochan J, Hall T, Esser K, Young JE, Chulay JD 1991. Immunization of owl monkeys with a recombinant protein containing repeated epitopes of a Plasmodium falciparum glycophorin-binding protein. Am J Trop Med Hyg 45: 548-559.

Bonnefoy S, Gysin J, Blisnick T, Gillotte M, Carcy B, Pereira Da Silva L, Mercereau-Puijalon O 1994. Immunogenicity and antigenicity of a Plasmodium falciparum protein fraction $(90-110 \mathrm{kDa}$ ) able to protect squirrel monkeys against asexual blood stages. Vaccine 12: 32-40.

Bonnefoy S, Mattei D, Dubremetz JF, Guillotte M, Jouin H, Ozaki LS, Sibilli L, Mercereau-Puijalon O 1988. Plasmodium falciparum: molecular analysis of a putative protective antigen, the thermostable $96-\mathrm{kDa}$ Protein. Exp Parasitol 65: 69-83.

Breuer WV, Ginsburg H, Cabantchik ZI 1983. An assay of malaria parasite invasion into human erythrocytes: the effects of chemical and enzimatic modification of erythrocyte membrane components. Biochim Biophys Acta 755: 263-271.

Camus D, Hadley TJ 1985. A Plasmodium falciparum antigen that binds to host erythrocytes and merozoites. Science 230: 553-556.

Chulay JD, Lyon JA, Haynes JD, Meierovics AI, Atkinson CT, Aikawa M 1987. Monoclonal antibody characterization of Plasmodium falciparum antigens in immune complexes formed when schizonts rupture in the presence of immune serum. $J$ Immunol 139: 2768-2774.

Dubois P, Dedet JP, Fandeur T, Rousslhon C, Jendoubi M, Pauillac S, Mercereau-Puijalon O, Pereira Da Silva L 1984. Protective immunization of the squirrel monkey against asexual blood stages of Plasmodium falciparum by use of parasite protein fractions. Proc Natl Acad Sci USA 81: 229-232.

Houghten RA 1985. General method for the rapid solid- 
phase synthesis of large numbers of peptides: specificity of antigen-antibody interaction at the level of individual amino acids. Proc Natl Acad Sci USA 82: 5131-5135.

Kochan J, Perkins ME, Ravetch JV 1986. A tandemly repeated sequence determines the binding domain for an erythrocyte receptor-binding protein of Plasmodium falciparum. Cell 44: 689-696.

Lyon JA, Haynes JD, Diggs CL, Chulay JD, PrattRossiter JM 1986. Plasmodium falciparum antigens synthesized by schizonts and stabilized at the merozoite surface by antibodies when schizonts mature in the presence of growth inhibitory immune serum. J Immunol 136: 2252-2258.

Lyon JA, Thomas AW, Hall T, Chulay JD 1989. Specificities of antibodies that inhibit merozoite dispersal from malaria-infected erythrocytes. Mol Biochem Parasitol 36: 77-86.

Merrifield RB 1963. Solid phase peptide synthesis. 1. The synthesis of a tetrapeptide. J Am Chem Soc 85: 2149-2154.

Orlandi PA, Sim BK, Chulay JD, Haynes JD 1990. Characterization of the 175-kilodalton erythrocyte binding antigen of Plasmodium falciparum. Mol Biochem Parasitol 40: 285-294.

Pasvol G 1984. Receptors on red cells for Plasmodium falciparum and their interaction with merozoites. Phil
Trans $R$ Soc Lond B 307: 189-200.

Perkins ME 1984. Surface proteins of Plasmodium falciparum merozoites binding to the erythrocyte receptor, glycophorin. J Exp Med 160: 788-798.

Perkins ME 1988. Stage dependent processing and localization of a Plasmodium falciparum protein of 130,000 molecular weight. Exp Parasitol 65: 61-68.

Perkins ME, Rocco LJ 1988. Sialic acid-dependent binding of Plasmodium falciparum merozoite surface antigen, Pf200, to human erythrocytes. J Immunol 141: 3190-3196.

Tam JP, Heath WF, Merrifield RB 1983. SN2 deprotection of synthetic peptides with a low concentration of HF in dimethyl sulfide: evidence and application in peptide synthesis. J Am Chem Soc 105: 6442-6455.

Trager W, Jensen J 1976. Human malaria parasites in continuous culture. Science 193: 673-675.

Urquiza M, Rodriguez LE, Suárez JE, Guzman F, Ocampo M, Curtidor H, Segura C, Truillo E, Patarroyo ME 1996. Identification of Plasmodium falciparum MSP1 peptides able to bind to human red blood cells. Parasite Immunol 18: 515-526.

Van Scharavendijk MR, Wilson RJ, Newbold CY 1987. Possible pitfalls in the identification of glycophorinbinding proteins of Plasmodium falciparum. J Exp Med 166: 376-390. 